\title{
Aspectos biológicos e danos de Pachycoris torridus em pinhão-manso
}

\author{
Sérgio Roberto Rodrigues ( $\left.{ }^{1}\right)$; Harley Nonato de Oliveira $\left({ }^{*}\right)$; Wilson Teixeira dos Santos ( $\left.{ }^{1}\right)$; \\ Alfredo Raul Abot (') \\ (') Universidade Estadual de Mato Grosso do Sul, Rodovia Aquidauana/CERA, Km 12, 79200-000 Aquidauana (MS). \\ (2) Embrapa Agropecuária Oeste, Caixa Postal 661, 79804-970, Dourados (MS). \\ (*) Autor correspondente: harley@cpao.embrapa.br
}

Recebido: 23/fev./2009; Aceito: 16/ago./2010.

\section{Resumo}

Pachycoris torridus (Hemiptera: Scutelleridae) é relacionado como uma praga de frutos e de sementes na cultura do pinhãomanso (Jatropha curcas L.). Este trabalho teve por objetivo estudar os aspectos biológicos e os danos que essa espécie pode ocasionar nessa cultura. Ovos, ninfas e adultos de P. torridus foram coletados e levados a laboratório, onde foram mantidos em câmaras climatizadas para estudo de aspectos biológicos. Para avaliação dos danos, adultos foram confinados em gaiolas no campo, contendo frutos em desenvolvimento. As posturas obtidas tinham em média 57,6 ovos. O período embrionário durou 12,7 dias, enquanto as ninfas de primeiro ao quinto ínstar duraram, respectivamente, 8,1; 10,9; 9,7; 11,6 e 11,7 dias. Da fase de ovo a adulto, o ciclo completou-se em 86,5 dias em média. A cópula durou em média 3h43min. Frutos em desenvolvimento e que receberam uma fêmea, um e dois casais para alimentação, reduziram em 63\%; 54\% e 85\% respectivamente, sua massa, quando comparados com frutos sem percevejos. As sementes formadas em frutos que receberam uma fêmea e um casal apresentaram redução de 99 e 58\% no teor de óleo respectivamente. Frutos com dois casais não armazenaram óleo nas sementes. Em frutos desenvolvidos infestados com um casal não se verificou alteração no tamanho e na redução ou alteração da massa, no tamanho e teor de óleo das sementes.

Palavras-chave: Jatropha curcas, biologia, Euphorbiaceae, Hemiptera, Scutelleridae.

\section{Biological aspects and damage of Pachycoris torridus on physic nut plants}

\begin{abstract}
Pachycoris torridus (Hemiptera: Scutelleridae) has been reported as a species that can damage fruit and seed of physic nut, Jatropha curcas L. The aim of this study was to evaluate the biological aspects and the damage of this stink bug species on J. curcas. Eggs, nymphs and adults of $P$. torridus were collected and maintained in a growth chamber. Some adults were confined in cages with developing fruits to damage assessment under field conditions. The postures had an average of 57.6 eggs. The incubation period was 12.7 days and the nymphal stage lasted 8.1, 10.9, 9.7, 11.6 and 11.7 days for the first, second, third, fourth, and fifth instars, respectively. The development from egg to adult was completed in 86.5 days. The copulation took 3 h43min. The presence of one female, one or two couples of stink bug caused decreases of 63, 54 and $85 \%$ in fruit weight when compared with control fruit (without insects). Seed oil content was reduced in 99\% and 58\% when fruits were attacked by a female or a couple. Those fruits with two couples had no oil in seed. For mature fruits, there was not observed any change due to insect presence.
\end{abstract}

Key words: Jatropha curcas, biology, Euphorbiaceae, Hemiptera, Scutelleridae.

\section{INTRODUÇÃO}

A cultura do pinhão-manso (Jatropha curcas L.) é considerada promissora para produção de biodiesel, pois suas sementes possuem elevado teor de óleo ( $25 \%$ a $40 \%)$, superior ao da maioria das oleaginosas utilizadas no mercado de biocombustíveis (ArRuda et al., 2004). Com a possibilidade de uso do pinhão-manso para a produção do biodiesel, várias áreas de cultivo e de pesquisas têm sido instaladas em diferentes regióes do Brasil.
Atualmente, estudos estão sendo realizados para melhor entender essa cultura. Trabalhos sobre o cultivo (Arruda et al., 2004), técnicas de propagação (NunEs et al., 2008) e nutrição mineral (Laviola e Dias, 2008; Silva et al., 2009), têm sido realizados. Apesar de ArRUDA et al. (2004) relatarem que são poucos os insetos que atacam o pinhão-manso, que possui como defesa a exsudação de látex cáustico quando há na planta algum ferimento, Franco e Gabriel (2008), Silva et al. (2008) e Oliveira et al. (2010) realizaram estudos 
demonstrando o potencial de dano de alguns artrópodes pragas a essa cultura.

Segundo Grimm (1999), na Nicarágua, Pachycoris klugii (Hemiptera: Scutelleridae) é relacionado como importante praga que danifica os frutos de J. curcas. No Brasil, $P$. torridus está relacionado à cultura do pinhão-manso, podendo também se alimentar de várias outras espécies vegetais (Michelotto et al., 2006; SÁNChEZ-Soto et al., 2004; SÁnchez-Soto e Nakano, 2002). Segundo SchMidT e BARCELlos (2007), adultos de P. torridus coletados em bromélias podem usar essa planta como possível local de hibernação.

Considerando a escassez de informaçóes a respeito da interação de $P$. torridus com o pinhão-manso, trabalho teve como objetivo estudar os aspectos relacionados à biologia e aos danos dessa praga a essa cultura.

\section{MATERIAL E MÉTODOS}

Adultos, ninfas e ovos de $P$. torridus foram coletados em uma área de aproximadamente 9 ha de plantio de pinhãomanso, localizada no Município de Anastácio (MS).

Os adultos e ninfas obtidos da coleta de campo foram mantidos em gaiolas de PVC $(10 \mathrm{~cm}$ de diâmetro e $25 \mathrm{~cm}$ de altura) ou em caixas de vidro $(35 \times 25 \times 25$ $\mathrm{cm}$ ), contendo folhas e frutos da planta, as quais foram cobertas com tecido de voil para evitar a saída dos insetos. Os recipientes foram vistoriados diariamente para obtenção de posturas.

Os ovos foram mantidos juntamente com fêmeas nas gaiolas ou nas caixas de vidro com mudas de pinhãomanso em vasos contendo solo, em câmara climatizada $\left(24 \pm 1^{\circ} \mathrm{C}\right.$ e $26 \pm 1^{\circ} \mathrm{C}$ e 12 horas de fotofase) até a eclosão das ninfas. Nas gaiolas e caixas de vidro foram adicionados frutos que foram substituídos a cada dois ou três dias, para alimentação de $P$. torridus. As mudanças de ínstares eram constatadas ao se notar as exúvias, e pelo próprio crescimento das ninfas. As variáveis biológicas avaliadas foram: duração do período embrionário, duração de cada ínstar, longevidade e viabilidade. As ninfas e os adultos tiveram suas dimensôes mensuradas com uso de paquímetro e a massa aferida com balança analítica.

Para a avaliação dos danos de $P$. torridus em frutos de pinhão-manso, foram realizados dois estudos, sendo um com frutos em desenvolvimento e outro com frutos desenvolvidos. No primeiro, realizado em campo, adultos foram confinados em gaiolas de tecido de voil, em plantas de pinhão-manso. A gaiola envolvia três frutos em desenvolvimento, com diâmetro aproximado de $1 \mathrm{~cm}$ cada um. Os adultos permaneceram confinados durante sete dias. Foram utilizadas as combinaçôes de uma fêmea, um macho, um casal ou dois casais para cada gaiola, além de frutos sem percevejos. Os cinco tratamentos foram repetidos cinco vezes, sendo utilizado o delineamento em blocos completos casu- alizados, adaptado do método usado por Grimm (1999). Nas inspeçôes, os adultos mortos eram substituídos.

No segundo estudo realizado em laboratório $(\mathrm{T}=25$ $\pm 1{ }^{\circ} \mathrm{C}$; 12 horas de fotofase), buscou-se avaliar o dano em frutos desenvolvidos. Foram utilizados dois tratamentos: no primeiro, o fruto recebeu um casal de adultos e o segundo foi mantido sem percevejos (testemunha), com quinze repetiçôes para cada tratamento. Cada casal permaneceu em contato com um fruto, por um período de cinco dias.

Os dados de diâmetro e massa de frutos, diâmetro e massa de sementes e teor de óleo das sementes foram obtidos após o amadurecimento dos frutos, sendo posteriormente submetidos à análise de variância e as médias comparadas pelo teste de Tukey $(\mathrm{p}<0,05)$.

\section{RESULTADOS E DISCUSSÃO}

Dos adultos coletados em campo, foram obtidas várias posturas, a partir das quais se iniciaram os estudos. Os ovos foram depositados em massas de 18 a 85 ovos ( $\mathrm{n}=$ 41), sendo constatados em média 57,6 ovos por postura. As posturas possuíam um conjunto de 4 a 9 linhas de ovos, contendo de 3 a 11 ovos por linha $(\mathrm{n}=15)$. Gabriel et al. (1988) amostraram posturas de $P$. torridus com médias de 65,71 e 87,21 ovos por postura, respectivamente, em Campinas e Tatuí.

Nos recipientes de criaçáo foram observadas ninfas de primeiro e segundo ínstares abrigando-se sob fêmeas que estavam protegendo as posturas. As ninfas permaneciam sob as fêmeas e sobre os ovos e nessas situaçōes as posturas que estavam sendo protegidas não originaram ovos (n =4). Provavelmente, as ninfas danificaram os ovos ou se nutriram destes, uma vez que foram observadas ninfas de segundo ínstar, predando as de primeiro ínstar $(\mathrm{n}=30)$.

Quando as massas de ovos eram manipuladas para realizar as mensuraçóes e quantificação dos ovos e em seguida eram devolvidas as gaiolas onde as fêmeas permaneciam, estas não protegiam mais os ovos e os abandonavam $(\mathrm{n}=20)$ definitivamente. Assim, a manipulaçáo dos ovos levava ao abandono da postura.

No período entre a postura e a eclosão, as fêmeas permaneceram sobre os ovos protegendo-os e, após a eclosão, as ninfas de primeiro e segundo ínstares foram observadas sob as fêmeas. À medida que atingiam o terceiro ínstar, não se observava mais esse comportamento. SANTOS et al. (2005) também observaram proteção de imaturos por fêmeas de $P$. torridus, enquanto Williams et al. (2005) verificaram esse comportamento em fêmeas de Pachycoris stallii.

A partir do terceiro ínstar, observou-se que as ninfas não permaneceram mais sob a proteção da fêmea. No entanto, quando oriundas de uma mesma postura, essas permaneceram agrupadas. Assim, foi comum observar grupos de 40, 50 ou mais ninfas com comportamento gregário até o quinto ínstar. Quando atingiram a fase adulta, não 
Tabela 1. Comprimento, largura e massa das fases de desenvolvimento de Pachycoris torridus em pinhão-manso, em laboratório ( $\mathrm{T}=26 \pm 1{ }^{\circ} \mathrm{C}$; fotofase de 12 horas)

\begin{tabular}{|c|c|c|c|c|c|c|}
\hline \multirow{3}{*}{ Estágio } & \multicolumn{2}{|c|}{ Comprimento } & \multicolumn{2}{|c|}{ Largura } & \multicolumn{2}{|c|}{ Massa } \\
\hline & $M \pm E P^{*}$ & $\Delta$ & $M \pm E P$ & $\Delta$ & $M \pm E P$ & $\Delta$ \\
\hline & \multicolumn{4}{|c|}{ mm } & \multicolumn{2}{|c|}{ mg } \\
\hline 10 ínstar & $3,4 \pm 0,03$ & $2,8-4,0$ & $1,7 \pm 0,02$ & $1,2-2,0$ & $2,7 \pm 0,08$ & $1,3-4,4$ \\
\hline 20 ínstar & $5,4 \pm 0,14$ & $5,0-5,7$ & $2,5 \pm 0,09$ & $2,4-2,8$ & $12,7 \pm 1,22$ & $9,7-15,4$ \\
\hline $3^{\circ}$ instar & $6,2 \pm 0,20$ & $6,0-6,4$ & $3,6 \pm 0,05$ & $3,6-3,7$ & $14,9 \pm 0,75$ & $14,1-15,6$ \\
\hline $4^{\circ}$ instar & $8,2 \pm 0,05$ & $7,4-8,9$ & $4,5 \pm 0,05$ & $3,9-5,3$ & $62,5 \pm 1,60$ & $35,5-82,5$ \\
\hline $5^{\circ}$ ínstar & $10,0 \pm 0,1$ & $8,0-11,0$ & $6,5 \pm 0,1$ & $4,2-7,4$ & $88,7 \pm 2,7$ & $45,0-150,8$ \\
\hline Adulto & $13,1 \pm 0,1$ & $12,0-14,5$ & $8,2 \pm 0,1$ & $7,0-10,0$ & $137,0 \pm 5,0$ & $67,5-184,8$ \\
\hline
\end{tabular}

${ }^{*}$ Média $(\mathrm{M})$; Erro-padrão (EP); Variação $(\Delta)$.

se observou mais esse comportamento. Peredo (2002) verificou que ninfas de $P$. klugii permaneceram em grupos de 30 a 40 indivíduos, considerando tal fato como possibilidade de aumento de chances para localizar alimento, além de defesa contra predadores e parasitóides.

Analisando-se o comprimento e a largura das ninfas, verificou-se que aumentaram cerca de 2,9 vezes em comprimento e 3,8 vezes em largura, do primeiro ao quinto íns$\operatorname{tar}$ (Tabela 1). Quando atingiram a fase adulta, verificou-se que do primeiro ínstar até esta fase houve aumento de 3,8 vezes no comprimento e de 4,2 vezes a largura (Tabela 1). $\mathrm{O}$ aumento da massa foi ainda mais pronunciado, pois do primeiro até o quinto ínstar houve aumento de 32,8 vezes e do primeiro para a fase adulta de 50,7 vezes (Tabela 1 ).

Santos et al. (2005), ao estudarem aspectos biológicos de $P$. torridus, verificaram para ninfas de primeiro ínstar, 2,7 $\mathrm{mm}$ de comprimento, valor inferior aos 3,4 $\mathrm{mm}$ observado para ninfas de primeiro ínstar no presente experimento (Tabela 1). As dimensóes obtidas de $P$. torridus são maiores quando comparadas às de ninfas de $P$. klugii, estudado por Peredo (2002), nas quais os comprimentos, do primeiro ao quinto ínstar eram de 2,07; 3,29; 4,$51 ; 6,82$ e $10,11 \mathrm{~mm}$, respectivamente. Para P. stallii, as ninfas possuem, do primeiro ao quinto ínstar, 2,57; 3,$27 ; 4,29 ; 5,23$ e $6,77 \mathrm{~mm}$ de comprimento respectivamente, segundo Williams et al. (2005); portanto, os comprimentos sáo inferiores aos de $P$. torridus, conforme observaçóes do presente experimento.

A partir do desenvolvimento embrionário e surgimento das ninfas, foram obtidas informaçôes sobre a duração das fases de desenvolvimento. Os ovos, ao serem depositados, possuíam coloração amarela, posteriormente rosa, em seguida vermelho e quando estavam próximos à eclosão, tornaram-se escuros. Williams et al. (2005) também observaram variaçóes de cores durante o desenvolvimento embrionário de P. stallii.

Nas posturas acondicionadas a $26^{\circ} \mathrm{C}$ verificou-se que houve desenvolvimento embrionário e de ninfas até o segundo ínstar; entretanto, a partir desse estágio, todas morreram.

$\mathrm{Na}$ temperatura de $24^{\circ} \mathrm{C}$, o período embrionário durou, em média, 12,7 dias. Do primeiro ao quinto ínstar, as ninfas duraram, em média, 8,1; 10,9; 9,7; 11,6 e 11,7
Tabela 2. Duração (média $\pm \mathrm{EP}^{*}$ ) das fases de desenvolvimento de Pachycoris torridus em pinhão-manso, em laboratório ( $\mathrm{T}=24 \pm 1$ ${ }^{\circ} \mathrm{C}$; fotofase de 12 horas)

\begin{tabular}{|c|c|c|}
\hline \multirow{2}{*}{ Fase } & Duração & Viabilidade \\
\hline & Dias & $\%$ \\
\hline Ovo & $12,7 \pm 0,51$ & 90,3 \\
\hline 1. ${ }^{\circ}$ instar & $8,1 \pm 0,13$ & 59,5 \\
\hline 2..$^{\circ}$ instar & $10,9 \pm 0,15$ & 57,0 \\
\hline 3. instar & $9,7 \pm 0,26$ & 57,9 \\
\hline $4 .^{\circ}$ instar & $11,6 \pm 0,79$ & 93,9 \\
\hline $5 .^{\circ}$ instar & $11,7 \pm 0,19$ & 100 \\
\hline Adulto & $93,0 \pm 5,01$ & 100 \\
\hline Ovo a adulto & $86,5 \pm 0,57$ & 16,7 \\
\hline
\end{tabular}

dias respectivamente; da fase de ovo até a emergência dos adultos, a duração média foi de 86,5 dias (Tabela 2). Pela duração do ciclo biológico de $P$. torridus, é possível inferir que duas a três geraçôes podem ocorrer durante o ano. Peredo (2002) estudou a biologia de P. klugii a $20^{\circ} \mathrm{C}$ e verificou que o período embrionário e os ínstares variaram de cinco a sete dias.

Várias ninfas coletadas no campo, ao atingirem a fase adulta no laboratório, a longevidade média era de 93 dias (30 a 150) $(\mathrm{n}=50)$. Quatro fêmeas demoraram 20 dias após atingir a fase adulta para realizarem a cópula; transcorridos mais 15 dias em média, iniciaram as oviposições.

Foi observado que algumas fêmeas coletadas no campo efetuaram uma postura $(n=4)$ e outras realizaram duas posturas $(n=3)$, ocorrendo em seguida o desenvolvimento embrionário. Uma fêmea coletada no campo ovipositou quatro vezes, e as posturas tinham 84, 63, 18 e 26 ovos, totalizando 191 ovos, não ocorrendo o desenvolvimento embrionário para nenhuma das quatro posturas.

Em quatro situaçóes foram observadas cópulas, com duração média de 3h43 min (mínima de 1 h30 min e máxima de $5 \mathrm{~h} 30 \mathrm{~min}$ ). As cópulas tiveram início entre as $9 \mathrm{~h}$ e $11 \mathrm{~h}$, com o término ocorrendo em três ocasiôes, no período da tarde. Machos e fêmeas durante a cópula posicionam seus corpos em direçôes opostas e permanecem unidos pela região posterior.

Durante o desenvolvimento dos estudos de biologia verificou-se alta mortalidade na fase de ninfa, com a via- 
Tabela 3. Diâmetro (D), comprimento (C), massa (M) de frutos e sementes e teor de óleo de pinhão-manso, sob quatro níveis de infestação de Pachycoris torridus $\left({ }^{1}\right)$

\begin{tabular}{|c|c|c|c|c|c|c|c|}
\hline \multirow{3}{*}{ Trat. } & \multicolumn{3}{|c|}{ Frutos } & \multicolumn{4}{|c|}{ Sementes } \\
\hline & D & C & M & D & C & $M$ & TO \\
\hline & \multicolumn{2}{|c|}{$\mathrm{mm}$} & g & \multicolumn{2}{|c|}{$\mathrm{mm}$} & g & $\%$ \\
\hline Testem. & $17,5 \mathrm{a}$ & $24,3 \mathrm{a}$ & $1,6 \mathrm{a}$ & $7,8 \mathrm{ab}$ & $15,7 \mathrm{ab}$ & $0,317 \mathrm{a}$ & $25,9 a$ \\
\hline 1 fêmea & $13,0 a b$ & $20,2 a b$ & $0,6 a b$ & $4,0 \mathrm{bc}$ & 10,6 bc & $0,052 \mathrm{a}$ & $1,0 \mathrm{c}$ \\
\hline 1 macho & $17,8 \mathrm{a}$ & $24,1 a b$ & $1,5 \mathrm{a}$ & $8,8 \mathrm{a}$ & $16,1 \mathrm{a}$ & $0,324 a$ & $15,6 \mathrm{~b}$ \\
\hline 1 casal & $12,4 a b$ & $18,6 a b$ & $0,7 a b$ & $7,7 \mathrm{ab}$ & $14,5 a b$ & $0,293 a$ & $11,0 \mathrm{~b}$ \\
\hline 2 casais & $9,4 \mathrm{~b}$ & 16,8 b & $0,2 \mathrm{~b}$ & $2,0 \mathrm{c}$ & $8,4 c$ & $0,016 \mathrm{a}$ & - \\
\hline CV (\%) & 24,79 & 18,50 & 59,92 & 40,15 & 21,36 & 84,09 & 17,50 \\
\hline
\end{tabular}

(1) Médias seguidas de letras iguais na coluna não diferem entre si pelo teste de Tukey, a $5 \%$ de probabilidade.

bilidade de ovo a adulto atingindo 16,7\% (Tabela 2). PEREDO (2002), ao estudar a biologia de P. klugii, observou alta mortalidade no segundo ínstar ninfal, sendo as causas desconhecidas. O mesmo autor discute a possibilidade de a alta mortalidade estar associada à mudança do habitat, além da necessidade de associação das ninfas com microorganismos simbiontes.

Ao mensurar os frutos em pinhão-manso, verificou-se menor diâmetro e comprimento para os frutos submetidos à alimentação de dois casais, diferindo dos frutos sem percevejos (Tabela 3). Na massa dos frutos em que havia uma fêmea para alimentação a reduçáo foi de cerca de $63 \%$, quando comparado com frutos sem percevejos, enquanto os frutos com um e dois casais tiveram sua massa reduzida em cerca de $54 \%$ e $85 \%$ respectivamente. Os frutos que receberam um macho pouco reduziram de massa, não diferindo dos frutos sem percevejos (Tabela 3). Grimm (1999) verificou que machos de P. klugii não reduziram a massa de frutos de pinhão-manso, sendo os maiores danos causados por ninfas e fêmeas.

As dimensóes e massa das sementes originárias dos frutos infestados com dois casais e uma fêmea tiveram redução acentuada; entretanto, na combinação de um macho e uma fêmea, esse processo não foi verificado (Tabela 3).

Os teores de óleo das sementes que receberam um macho, um casal e uma fêmea foram reduzidos em $40 \%$, $58 \%$ e $99 \%$ respectivamente, quando comparados com o de frutos sem percevejos, com diferenças entre os tratamentos (Tabela 3). No tratamento com dois casais não foi possível determinar o teor de óleo, em face das pequenas dimensôes das sementes. Nesse tratamento, verificaram-se danos expressivos nos frutos e nas sementes, caracterizando a capacidade dos adultos em danificar os frutos em formação. Foi verificado também queda de frutos, fato não observado nos demais tratamentos.

O maior dano em frutos e sementes foi provocado por fêmeas, o que pode ser explicado pela sua necessidade de adquirir reservas nutricionais para o desenvolvimento de óvulos; além disso, após a postura, as fêmeas permanecem protegendo os ovos, precisando, portanto, de reservas adquiridas.
Frutos desenvolvidos infestados com um casal não diferiram com relaçáo ao comprimento, diâmetro e à massa de frutos, além de comprimento, massa e teor de óleo das sementes, quando comparadas com o tratamento-testemunha.

Quando os frutos estavam em formação e foram infestados com dois casais, observaram-se quedas, além das reduçóes nas dimensóes e na massa de frutos e dimensóes, massa e teor de óleo das sementes. Entretanto, quando o fruto estava desenvolvido, a presença de um casal de $P$. torridus não causou danos nessa estrutura. Assim, torna-se importante realizar a proteção dos frutos e sementes durante o crescimento. GRIMM (1999) verificou que quanto menor o diâmetro dos frutos que receberam infestaçôes de $P$. klugii, maiores foram as porcentagens de queda de frutos de pinhão-manso.

\section{CONCLUSÃO}

Em condiçóes de laboratório $\left(\mathrm{T}=24 \pm 1^{\circ} \mathrm{C} ; 12\right.$ horas de fotofase), o ciclo de ovo a adulto de P. torridus em pinhão-manso dura em média 86,5 dias. As fêmeas de P. torridus causam danos aos frutos e às sementes dessa planta. Frutos em desenvolvimento são mais danificados do que frutos já desenvolvidos.

\section{AGRADECIMENTOS}

À Fundação de Apoio ao Desenvolvimento do Ensino, Ciência e Tecnologia do Estado de Mato Grosso do Sul - FUNDECT, e à Empresa de Mineração e Metálicos Ltda - MMX, pelo apoio financeiro e a disponibilização da área.

\section{REFERÊNCIAS}

ARRUDA, F.P.; BELTRÃO, N.E.M.; ANDRADE, A.P.; PEREIRA, W.E.; SEVERINO, L.S. Cultivo de pinhão-manso (Jatropha curcas L.) como alternativa para o Semi-Árido nordestino. Revista Brasileira de Oleaginosas e Fibrosas, v.8, p.789-799, 2004. 
FRANCO, D.A.S.; GABRIEL, D. Aspectos fitossanitários na cultura do pinhão manso (Jatropha curcas L.) para produção de biodiesel. O Biológico. v.70, p.63-64, 2008.

GABRIEL, D.; CALCAGNOLO, G.; TANCINI, R.S.; DIAS NETO, N.; PETINELLI JUNIOR, A.; ARAÚJO, J.B.M. Estudo com o percevejo Pachycoris torridus (Scopoli, 1772) (Hemiptera: Scutelleridae) e seu inimigo natural Pseudotelenomus pachycoris Lima, 1928 (Hymenopotera; Scelionidae) em cultura do pinháo paraguaio Jatropha spp. O Biológico, v.54, p.17-20, 1988.

GRIMM, C. Evaluation of damage to physic nut (Jatropha curcas) by true bugs. Entomologia Experimentalis et Applicata, v.92, p.127-136, 1999.

LAVIOLA, B.G.; DIAS, L.A.S. Teor e acúmulo de nutrientes em folhas e frutos de pinhão-manso. Revista Brasileira de Ciência do Solo, v.32, p.1969-1975, 2008.

MICHELOTTO, M.D.; SILVA, R.A.; BUSOLI, A.C. Percevejos (Hemiptera: Heteroptera) coletados em aceroleira (Malpighia glabra L.) em Jaboticabal, SP. Arquivos do Instituto Biológico, v.73, p.123-125, 2006.

NUNES, C.F.; PASQUAL, M.; SANTOS, D.N.; CUSTÓDIO, T.N.; ARAÚJO, A.G. Diferentes suplementos no cultivo in vitro de embriōes de pinhão-manso. Pesquisa Agropecuária Brasileira, v.43, p.9-14, 2008.

OLIVEIRA, H.N.; SILVA, C.J.; ABOT, A.R.; ARAÚJO, D.I. Cigarrita verde em cultivos de Jatropha curcas en el Estado de Mato Grosso do Sul, Brasil. Revista Colombiana de Entomologia, v.36, p.52-53, 2010.
PEREDO, L.C. Description, biology, and maternal care of Pachycoris klugii (Heteroptera: Scutelleridae). Florida Entomologist, v.85, p.464-473, 2002.

SÁNCHEZ-SOTO, S.; MILANO, P.; NAKANO, O. Nova planta hospedeira e novos padróes cromáticos de Pachycoris torridus (Scopoli) (Hemiptera: Scutelleridae) no Brasil. Neotropical Entomology, v.33, p.109-111, 2004

SÁNCHEZ-SOTO, S.; NAKANO, O. Ocorrência de Pachycoris torridus (Scopoli) (Hemiptera: Scutelleridae) em acerola (Malpighia glabra L.) no Brasil. Neotropical Entomology, v.31, p.481-482, 2002.

SANTOS, J.C.; SILVEIRA, F.A.O.; ALMEIDA, F.V.M.; FERNANDES, G.W. Ecology and behavior of Pachycoris torridus (Hemiptera: Scutelleridae): new host plant, color polymorphism, maternal care and parasitism. Lundiana, v.6, p.107-111, 2005.

SCHMIDT, L.S.; BARCELLOS, A. Abundância e riqueza de espécies de Heteroptera (Hemiptera) do Parque Estadual do Turvo, Sul do Brasil: Pentatomoidea. Iheringia, v.97, p.73-79, 2007.

SILVA, P.H.S; CASTRO, M.J.P; ARAÚJO, E.C.A. Tripes (Insecta: Tripidae) associados ao pinhão-manso no Estado do Piauí, Brasil. Revista Brasileira de Oleaginosas e Fibrosas, v.12, p.125-127, 2008.

SILVA, E.B.; TANURE, L.P.P; SANTOS, S.R.; RESENDE JUNIOR, P. S. de. Sintomas visuais de deficiências nutricionais em pinhão-manso. Pesquisa Agropecuária Brasileira, v.44, p.392-397, 2009.

WILLIAMS III, L.; COSCARÓN, M.C.; DELLAPÉ, P.M.; ROANE, T.M. The shield-backed bug, Pachycoris stallii: description of immature stages, effect of maternal care on nymphs, and notes on life history. The Journal of Insect Science, v.5, p.29, 2005. 